\title{
ERRATUM
}

\section{Internalizing early memories of shame and lack of safeness and warmth: The mediating role of shame on depression - ERRATUM}

Marcela Matos, José Pinto-Gouveia and Cristiana Duarte

doi:10.1017/S1352465812001099, Published by Cambridge University Press. First published online 25 March 2013

Due to a typesetting error we have repeated Figure 2 also as being Figure 1.

The correct Figure 1 is shown below

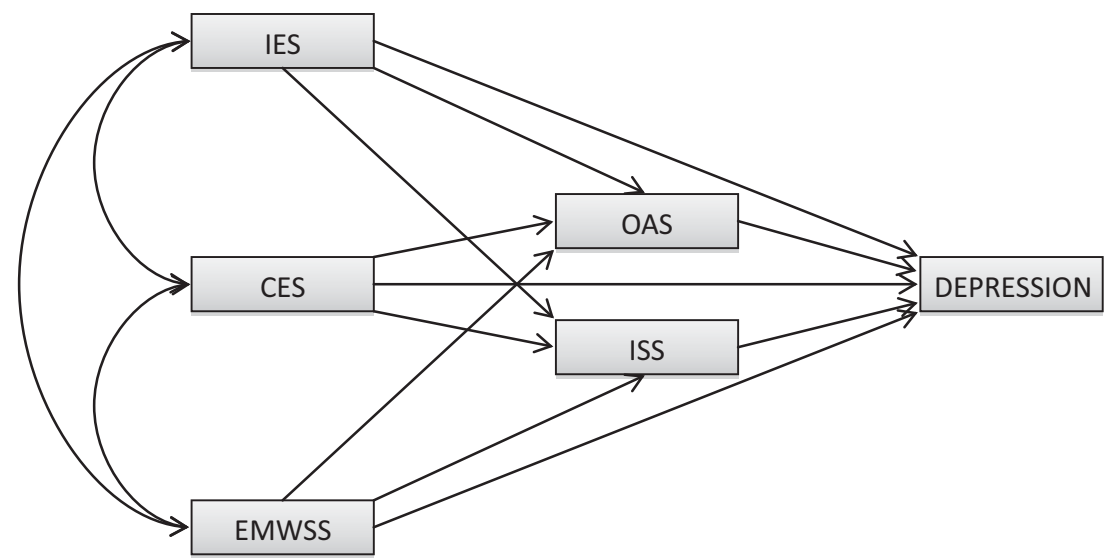

Figure 1. The theoretical model

Key: CES = Centrality of shame memories; IES-R = Shame traumatic memory; EMWSS = Early memories of warmth and safeness; OAS = External shame; ISS = Internal shame; Depression = DASS42 depression subscale

\section{Reference}

Matos, M. et al. (2013). Internalizing early memories of shame and lack of safeness and warmth: The mediating role of shame on depression. Behavioural and Cognitive Psychotherapy, 41, 479-493. 